Marta POSTUŁA, PhD, Professor

Faculty of Management, University of Warsaw

e-mail: mpostula@wz.uw.edu.pl

ORCID: 0000-0001-5502-9722

DOI:10.15290/oes.2018.03.93.12

\title{
IMPACT OF PERFORMANCE BUDGETING ON THE STRUCTURE OF EXPENDITURE: THE EXPERIENCES OF EURO AREA COUNTRIES
}

\section{Summary}

Goal - The aim of the paper is to assess to what degree the advancement in the implementation of instruments from the area of the so-called performance budgeting contributes to the rational management of public expenditure structure.

Research methodology - Qualitative research based on descriptive analysis using extensive subject literature (chiefly foreign) composed of monographs, journals, scientific studies, and reports of international institutions helps the author solve research problems and achieve the paper's objective. Among the methods used are also deductive and inductive reasoning, and comparative analysis. Qualitative studies employ the method of systemizing statistical information, based on analysis of reference statistical data, and the methodology of statistical dependence.

Score - The research results show that irrespective of the detailed legal provisions introduced at the EU level under the modified Stability and Growth Pact, the decisions regarding the structure of expenditures are made on the basis of election platforms. The structure of expenditures cannot be modelled because it depends on the political decisions made in individual countries. Additionally, no impact of performance budgeting on the structure of expenditures in the euro area countries has been found. The two identified groups-spending on defense and housing policy - are rigid expenditures and cannot be part of fiscal consolidation in the short term.

Uniqueness/value - Not only does the paper discuss concepts related to the models of contemporary economic processes, but it also contributes to the debate on the extent of state interference in the sector of financial institutions in the global economy. The conducted research is an original attempt to explain the mechanism of the analysed phenomenon and to illustrate its progress in the changing economic environment.

Keywords: public spending, performance budgeting, fiscal adjustment, public services

JEL classification: H50, H61, E62

\section{Introduction}

Economic approach to fiscal policy ought to involve striving for steady economic growth and long-term stability of public finances. When countries pursue a reduction in the level of public debt and budget deficit, they undertake consolidation activities. The consolidation of finances should be understood as a policy aimed at 
improving public finances by means of reducing budget deficit and maintaining the ratio of public debt to GDP at a secure level. The efficiency of a consolidation strategy ought to be assessed not only through the prism of the degree of deficit reduction in the public finance sector, but also by assessing the stability of achieved consolidation and the impact of the undertaken activities on socio-economic development. This is because attempts to reduce expenditures may have a negative impact on economic growth and social development.

The assessment of public spending on economic growth is far from straightforward and evolves along with the development of economic thought. Theories of growth vary in their view of the direction and consequences of the redistribution of incomes (and, ultimately, of public expenditure). Depending on the school of economic thought (new classical, neoclassical, neo-Keynesian, or the theory of real business cycle), an increase in public expenditure for economic growth may be believed to have positive, neutral or negative consequences. However, irrespective of the theory, it is crucial that decisions pertaining to practical actions are based on premises accounting for the financial dimension and the socio-economic consequences which may result from these actions.

The paper focuses on analysing the impact of the advancement of particular euro area countries in using the so-called performance budgeting on their expenditure structures and levels of fiscal adjustment. The author presents the results of research aimed to determine the extent to which advancement in implementing instruments from the area of performance budgeting influences the management of public spending and the level of fiscal adjustment. The consequences of spending public funds are usually evaluated when an increase in outlays is observed, e.g. on the implementation of a projector on enhancing its scale. Performance budgeting tools ought to be a useful instrument also in the period when expenditure needs to be reduced for some reason or another.

Fiscal adjustment, which is regarded as a reduction in fiscal deficit, should entail low social costs in these countries because the authorities have detailed data regarding public expenditure and the reductions should be made in such a way that the negative impact of reduced outlays on the quality of public services is minimal. The paper offers a quantitative verification of the following hypothesis: in countries which are advanced in implementing performance budgeting, the adjustment (reduction) of expenditure ought to be discretionary (varying scope of cuts in particular areas) instead of merely statistical, i.e. one which affects all types of expenditure to the same extent.

Mixed methodology is used for empirical verification of the hypotheses ensuing from the presented research problem, with regards to both qualitative and quantitative research. The former is based on descriptive analysis, while the latter uses the methods of systematization of statistical information based on analysis of reference statistical data and the proposed logit model. 


\section{Public spending as the impulse of economic growth}

The turn of the $20^{\text {th }}$ and $21^{\text {st }}$ centuries witnessed intense research into and development of methods of public management. The greatest interest was focused on the quality of public expenditure. It was then that a new concept of the impact of public expenditure on economic growth was developed [OECD, 2012, pp. 102-103]. There still remains, however, the basic dilemma regarding the effects of expenditure on growth - programmes implemented by means of public spending may have a variety of positive impacts on economic growth. To investigate the effects of public expenditures on growth, they have to be divided into four categories.

The first category comprises interest payments - the costs of debt service. This kind of expenditure always has a negative influence on growth and employment. The use of funds for other purposes usually ought to be more productive. The second category includes pensions and disability benefits, expenditure on collective consumption and public sector salaries. Up to a relatively high level, expenditure on these purposes has a positive impact on growth, while too high a level (caused, among other things, by excessive wage growth in the public sphere)may have the opposite effect. High expenditures in this category could also restrict spending which could potentially increase efficiency [Hall, 2014, pp. 1223-1243]. For example, a very high level of expenditure on pensions may have a negative impact on savings and the accumulation of capital. High pensions or earlier retirement benefits may also have negative influence on employment. High costs of labour in the public sector can increase inflation and affect the functioning of the labour market (imitation effect in the process of negotiating wages, etc.). The third category comprises disability social benefits, expenditure on preventing social exclusion, housing, unemployment benefits and family allowances. Public expenditure on these purposes may have positive implications for efficiency, provided that it does not exceed certain limits. If it does, growth can be adversely affected as it may lead to permanent dependence of beneficiaries on social aid, thus giving rise to serious moral dilemmas. Reducing public expenditure in this category to a level below a certain minimum is also harmful for the economy because it prevents many people from participating in the labour market, leads to the extension of the zone of extreme poverty, and hampers the reintegration of excluded individuals. Very low levels of funds for counteracting unemployment may reduce the efficiency of an economy by discouraging employment-seeking efforts and cause suboptimal division of labour. The fourth category includes expenditure on education, health care, active forms of combating unemployment, research and development, as well as public investments. This group of expenditures has a thoroughly positive impact on the economy. Only when the level of expenditures becomes extremely high can negative consequences occur. However, empirical verification of this claim is difficult because it applies to levels of expenditure which is unheard of in European countries.

As regards the first of the above-presented concepts, analyses of the impact of expenditure on economic growth are based on detailed structures of public expenditures, while the basic theories of growth are focused on the analysis of the global 
amounts of public expenditure. Examination of various types of expenditures leads to new conclusions that differ from the ones drawn within the framework of the basic theories of growth.

The sources of economic growth analysed according to the duration and stability of their effects can be divided into long-term and short-term ones. Long-term sources are connected with the supply side and with the changes in the effectiveness of production factors, whereas short-term sources of growth are related to changes in both internal and external demand. As was mentioned, some types of public spending may positively affect growth (provided that certain conditions are met). Decisions regarding the allocation of public spending may concern very different time horizons. Expenditures on tangible assets usually require long-term implementation and yield measurable effects only after the completion of the entire investment process. Other types of expenditure relatively rapidly translate into consumption. It should be noted, however, that also this latter type of expenditure can assume the form of relatively fixed monthly or annual inflows. Irrespective of the ultimate division into investments or consumption, public expenditure is characterized by low flexibility. Allocation decisions of public authorities usually involve expenditures which are specified even in terms of value in the existing legislation (budget acts aside) or expenditures aimed at implementing selected directions of public intervention (in this case, indicated in the budget act), which have an impact on the overall level of consumption and investments resulting from the use of public funds [Boris, 2014, pp. 42-61].

The recorded growth of interest in the effects of structural changes in fiscal policy has been considerable in recent years, which is hardly surprising given that the majority of highly developed countries must endeavour to rectify fiscal imbalance. Therefore, the question arises: how to adjust the structure of expenditures? In many countries, the levels of public deficit and public debt were relatively high even before the onset of the 2008 financial crisis. The need to alleviate the effects of the crisis (by means of automatic stabilizers and discretionary measures, such as assisting the public sector) caused public debt to soar, even in those countries where budget surpluses had been previously recorded, e.g. in Spain or Ireland. Contrary to popular opinion, the necessity to reduce budgetary imbalance is not usually imposed by the cost of financing public debt. Dell'Erba, Mattina [2013] estimated that only around a third of the fiscal adjustment cases had been enforced by financial markets which refused to finance debt or had imposed such high costs of financing that governments were compelled to substantially reduce their borrowing needs. In general, downsizing the scale of fiscal imbalance happened as a result of conscious decisions taken by countries obliged not to exceed a permitted limit of public debt (as is the case in the $\mathrm{EU}$ ) or was a response to the expectations of the public (taxpayers), aware of the negative consequences of public debt. 
In view of the above, it is essential that a more thorough analysis is made of how the different categories of public expenditure, defined according to $\mathrm{COFOG}^{1}$, affect the level of consumption and investments. Changes in the level of particular groups of expenditure have diverse influence on the dynamics of the components of demand.

Expenditures connected with domestic activities are relatively neutral for the economy. In this group, an important exception are public debt transactions, which constitute a genuine and inflexible expenditure priority. Unhindered execution of these expenditures and their maintenance at an optimal level (which is connected with controlling the size of the public debt) is a prerequisite for a healthy fiscal balance. Excessive expenditure on debt servicing, which also belongs this category, especially incurred from the deficit (if the public finance sector is unable to achieve a primary surplus) may lead to the situation when banks shrink their lending activities for entrepreneurs and the rate of economic growth suffers.

Under the COFOG classification, the second group of expenditures comprises spending on national defence. For some countries (especially those with large economic potential), these transfers constitute a stabilizing factor which reinforces both investment and consumption demand. The consequences of excessive expenditures in this category (especially for small and medium countries involved in domestic and international conflicts) are not positive, and frequently cause excessive debt and tensions in the payment balance. Additionally, the involvement of a country in a military conflict results in other negative phenomena such as: loss of life, health and property, which additionally undermines the rationale for expenditures in this area. Expenditures on security and public order maintained at the optimal level ensuring good functioning of relevant national services (including the judiciary) enable sustainable economic growth. Changes in the level of expenditure in this category in the short and medium term ought to be neutral for growth.

The next three groups of expenditures identified in the COFOG classification (economic affairs, environmental protection ${ }^{2}$, housing and municipal economy) have a strong impact on investments and a slightly smaller impact on consumption. This group of expenditures includes large projects- both infrastructural (road, railway and air transport) and environmental ones (water management, waste disposal, utilities and housing).

The last four groups of expenditures in the COFOG classification mainly have a bearing on the level of consumption. The first group comprises transfers on public health, which include outlays on medication and medical equipment and, above all, medical services: public health care, hospitals and outpatient clinics. The recent decades have witnessed a dramatic development of medical services, which - given the ageing of society - leads to increasingly high public and private expenditures in this

1 COFOG - Classification of the Functions of Government, developed jointly by: UN, OECD and EC-Eurostat, see: http://eur-lex.europa.eu.

2 The category of expenditure on environmental protection was identified in 2001, which demonstrates increasing interest of the state in activities from this area. 
category, thus boosting investments and consumption. The second analysed category (the smallest one) in this group of public expenditures regards the leisure industry, culture and religion. It has influence on consumption (rather moderate, owing to its dimension, but essential for the quality of life and social welfare). Another category concerns expenditure on education, which broadly encompasses public expenditure on education of children and youth, from kindergartens, primary and secondary schools to universities and other educational services. Expenditure on education constitutes an important factor of long-term competitiveness of economies, stemming from enhancement of social capital. The last and the most comprehensive category of expenditures - social protection - includes most types of spending in the subsector of social insurance: payment of pensions and disability benefits, family and children benefits, unemployment benefits, sickness and disability benefits. Public expenditure on social protection to the greatest degree translates into consumption. It is also subject of particular attention of fiscal policy owing to the phenomenon of population ageing and its long-term consequences for both the stability of public finances and sustainable economic growth.

\section{Transparency and principles of public finance management}

The quality and transparency of the public finance system is of major importance for the assessment of the actual condition of a country's finances and the state of its fiscal policy. The scale of complexity of public systems and the ambiguity of the principles of macroeconomic statistics make them difficult to analyse. This is particularly visible in the discrepancies between data regarding budget balance and those regarding its impact on the level of public debt. They ought to be closely linked with one another. However, this is not a rule because there are a number of possibilities to classify transactions in such a way that the level of public debt is not directly related to the current budget balance, and the other way round. Such discrepancies greatly hamper the evaluation of government fiscal policy by domestic entities (taxpayers, beneficiaries of public goods) and foreign entities, both international organizations and the purchasers of government securities. Comparative research [Sly, Weber, 2013] confirms that countries characterized by the highest degree of transparency of public finances record the fewest discrepancies in data describing the state of public finances, i.e. their debt levels directly result from the budget balance. Therefore, the transparency of state finances is of crucial importance for the reliability of research concerning the effects of fiscal policy because it guarantees the credibility of basic data reflecting the state of public finances. One of the methods to enhance the transparency and efficiency of public institutions is the use of tools provided by performance budgeting.

In the literature, there is a considerable degree of confusion surrounding the very term 'performance budgeting.' Authors disagree as to both the definition the concept and the purpose of using the techniques it proposes. Naturally, public management combines elements from several social sciences which focus on the functio- 
ning of the public sector: economics, finances, management, political science, social psychology and sociology, each of them approaching the subject from a different angle. Perhaps the simplest definition of performance budgeting is offered by the OECD [2003, p. 7]: "budgeting that links the funds allocated to measurable results". At first glance, the phrase seems straightforward enough, but the word 'budgeting' can refer to a variety of things, like designing a budget (allocating resources to tasks/institutions/areas of activity), presenting a budget, or assessment/evaluation of the way public funds are spent. The purposes of introducing new methods of public finance management are also varied as they can include better allocation of resources (distribution of funds among areas and institutions), or improvement of the efficiency and effectiveness of institutions. The new solutions can also be aimed at enhancing the transparency of the public finance system so as to make it possible to conduct objective assessment of public policies. Robinson and Brumby (2005) point out that the aforementioned theoretical questions, along with the notorious problems with measuring the effects of public policies ${ }^{3}$, make it quite difficult to conclude definitely whether performance budgeting is an efficient method of managing public finances.

According to OECD research, the results of which were published in 2007, 2011 and 2016, almost all the OECD countries, i.e. 29 among the 33 analysed countries, declared that to analyse the degree to which public expenditures (programmes) they used information regarding products (i.e. the quantity, quality and value of public goods and services) and results understood as the impact on socio-economic indicators. Additionally, 24 countries employed synthetic measures concerning products and results, whereas in 12 countries other forms of information on non-financial effects of public tasks were used. What is far more important is how efficiency information is processed by public administration. Collected data imply that it is not fully exploited. Nineteen countries used efficiency information for justifying the current allocation of funds. In 18 countries, it was used for specifying objectives and managing programmes, while in 15 of them the information proved useful for making revision plans and programmes. The results of the research conducted by the OECD indicate that only a minority of the 33 analysed countries claimed that data regarding effectiveness had a direct impact on the allocation of public expenditures. In 12 cases, the possibility to modify programmes was indicated as a consequence of using efficiency information, in 10 - budgetary re-allocation across programmes was mentioned, whereas only in 9 countries the obtained effects involved a reduction in expenditure [Postuła, 2017].

The experiences of OECD countries also prove that the measured data is sometimes irrelevant to what is manageable in practice. The cited OECD study implies

3 The greatest difficulty lies in measuring the impact of public policies. While it is relatively easy to quantitatively describe the outcomes of the activity of public institutions, their influence, or desired changes in a given area, are extremely difficult to measure accurately. There are also objective doubts as to whether observed changes result from the actions of the public sector or whether other factors, largely independent of the state, are more relevant. 
that another serious problem is inadequate reaction to unsatisfactory efficiency. The accuracy of measuring the outcomes of implemented tasks varies across state administration units, depending on their structure of assignments. Despite many years of experience, the final results of some diverse public tasks are often difficult to identify and quantify.

On the basis of the aforementioned results of the OECD over view, it can be said that even though the assessment of efficiency is used in the management of public programmes, it does not constitute the major criterion for making decisions regarding the allocation of public funds. On the other hand, however, the results confirm that efficiency information does play quite an important role in public management, which is frequently contested as the allocation of public funds is ultimately decided on the basis of a whole set of criteria, among which there are data on efficiency, if available. Lack of such information substantially reduces the quality of public management processes.

The research conducted by the OECD shows that governments increasingly often include efficiency data in the information they publish. One of the aims of such activities is to "promote" those administrators who achieve better efficiency, but also to boost the transparency of public spending. OECD member states widely differ in their approaches to management by objectives and there is no agreement as to which system is optimal [Shrithongrung, Kriz, 2014, pp. 912-928]. Nevertheless, in the published studies, the OECD makes assessments of the system of performance budgeting in several categories. Unfortunately, the research results directly prove that although OECD member states present efficiency information, they rarely use it for the allocation of funds.

In the analyses of the surveys conducted by the OECD it is difficult to notice any direct activities undertaken by countries to strengthen the role of management by objectives in allocating public funds and accounting for implementation of public tasks. Meanwhile, such direction of activity should have been expected of the EU countries, not only because of the rising awareness of the necessity of fiscal consolidation, but also due to the fact that relevant regulations regarding this area had been introduced at the EU level. In 2011, the European Union published a Council Directive on the requirements for budgetary frameworks of the Member States ${ }^{4}$. In accordance with the definition adopted in the directive, budget frameworks are a collection of settlements, procedures, rules and institutions that constitute the basis for running an effective budget policy in the sector of central and local government institutions. The directive structures the frameworks as follows: systems of accounting and statistics; prognostic procedures; numerical fiscal rules; budget process procedures; medium-term budget frameworks that extend the horizon for fiscal policymaking beyond the annual budgetary calendar; the transparency of processes; the relations between public organs in all subsectors.

4 Council Directive 2011/85/EU of 8 November 2011 on requirements for budgetary frameworks for the Member States, Official Journal of the European Union L 306/41 from 23.11.2011. 
However, a reading of the convergence programmes prepared by European countries does not confirm that the issue of quality and measurability of the effects of public expenditures is an area of special interest on the part of fiscal authorities. It is difficult to find there any clues indicating that efficiency information is used in the course of activities aimed at reducing fiscal imbalance.

Also in the OECD, a degree of inconsistency can be observed as regards the approach to using qualitative information. An OECD report on the state of public finances of the member states, published at the end of 2012, presentsa classification of countries according to the need of fiscal consolidation (in descending order) [OECD, 2012, p. 24]. However, the classification does not take into consideration (at least apparently) the qualitative approach to the allocation of public funds as an element of the process of consolidation.

Times of crisis are a real test for the effectiveness and usefulness of the instruments of economic policy. From this point of view, initial findings indicate that the set of activities defined as performance budgeting did not prove to be useful in the period when the pressure on the efficiency of public expenditure ought to be particularly high. Objective circumstances force governments to reduce the overall level of public expenditure, but the reductions should be made in such a way priority public tasks continue to be funded and only those expenditures which yield the worst results are cut. In a review of the changes in the systems of public finances in OECD countries which resulted from the worsening of the budget balance during the financial crisis, Robinson [2016] notes that both the aims and instruments of fiscal adjustment entirely overlook the opportunities provided by performance budgeting. The desired structure of expenditure and its priority settings are not indicated, the possible effects of reductions in outlays on particular areas of state activity are not analysed. The aims are defined in a purely quantitative manner at the aggregated level, i.e. the target level of fiscal balance (the size of deficit and public debt) is set and the overall level of expenditure and the necessary scale of its reduction are specified. The instruments which serve to achieve macroeconomic objectives include such mechanisms as imposed limits of expenditure or inclusion of the so-called fiscal rules into the legal system (e.g. quantitative limits of public debt).

\section{Description of research method}

The aim of the research is to check to what degree fiscal adjustment is related to active management of the structure of public expenses, i.e. to what extent changes in the scale of fiscal imbalance are associated with the dynamics of particular categories of expenditure.

The study uses panel data models. Panel data include variables observed in at least two dimensions, e.g. space and time (many objects observed over many periods). Analyses of panel data can be conducted through estimations using the classical method of least squares, the fixed effects model, and the random effects model [Gruszecki, 2002, p. 47]. The importance of panel models is emphasized by Griliches 
and Intriligator [2007, pp. 1248-1318]. Baltagi [2003] also widely used panel models for econometric analyses. To achieve the research objective, analyses of panel data (balanced panel) were conducted and two panel models were constructed using the generalised maximum likelihood method: a fixed effects model and a random effects model (the experiences gathered so far show that this type of model is not appropriate for the data used, but nevertheless an attempt was made to apply it). The research sample comprises selected euro area countries of the European Union.

First, an attempt was made to identify what factors/types of expenditure have an impact on the scale of fiscal adjustment in the analysed countries. This was the starting point for further investigations regarding the influence of performance budgeting on their structure because, as has been mentioned previously, this instrument can be understood and implemented in a variety of ways (in some cases it has a partial character and refers to a certain group of expenditures identified in the COFOG classification).

The degree of advancement in the implementation of performance budgeting is defined on the basis of surveys conducted by the OECD [2015]. Particular countries are assessed based on whether they use instruments from the following areas in public finance management:

- General guidelines and definitions for the performance budgeting process;

- Standard template(s) for reporting performance information back to the CBA;

- Standard performance rating system;

- Standard set of performance indicators and/ or targets);

- Standard ICT tool/ application for entering and reporting performance information to the $C B A$.

Depending on whether they answer the questions in the affirmative or in the negative, the countries are ranked from 0 (the instruments are not used in any area or the country does not use PB at all) to 5 (all the principles of using PB are observed in the practice of public finance management).

The starting point for the conducted analysis was the scale of fiscal adjustment in the studied period. In the constructed model, it was the dependent variable.

The independent variables comprised 171 variables chosen on the basis of substantive knowledge (a set of potential independent variables) and were later selected using Hellwig's method. When constructing the panel model, it was expected that the random components for each country in the subsequent years would be correlated with one another and thus may not be treated as separate observations of basic models for data that are not a panel. The basic model specification must be extended to contain a segment which measures country-specific unobserved heterogeneity. The general form of the model effects is [Greene, 2002]:

$$
\begin{gathered}
y_{i t}^{*}=x_{i t}^{\prime} \beta+v_{i t}+u_{i}, i=1, \ldots, n, t=1, \ldots, T_{i} \\
y_{i t}=1, \text { if } y_{i t}^{*}>0.0 \text { inp. } p .
\end{gathered}
$$

where: 
$u_{i}-$ country-specific unobserved heterogeneity

The fixed effects logit model is a special case of the above model, used to analyse data regarding factors of fiscal adjustment:

$$
\begin{gathered}
y_{i t}^{*}=\alpha_{i} d_{i t}+x^{\prime}{ }_{i t} \beta+\varepsilon_{i t}, i=1, \ldots, n, t=1, \ldots, T_{i} \\
y_{i t}=1, \text { if } y_{i t}^{*}>0, .0 \text { inp. } p .
\end{gathered}
$$

where:

$d_{i t}=1$ for country $\mathrm{i}$, otherwise 0.

The log-likelihood for this model is therefore:

$$
\ln L=\sum_{i=1}^{n} \sum_{t=1}^{T_{i}} \ln P\left(y_{i t} \mid \alpha_{i}+x^{\prime}{ }_{i t} \beta\right),
$$

where:

$\mathrm{P}$ - likelihood of the observed outcome

Using a thus defined model, research was conducted on the sample of 171 observations: data for 19 euro area countries in the years 2007-2015 for the adopted variables presented in table 1 .

TABLE 1

\section{Variables used in the model}

\begin{tabular}{|l|l|l|}
\hline \multicolumn{1}{|c|}{ Variable } & \multicolumn{1}{|c|}{ Name } & \multicolumn{1}{|c|}{ Coding } \\
\hline Fiscal adjustment & F_ADJ & $\begin{array}{l}\text { Zero-one variable which takes value 1 if General govern- } \\
\text { ment primary net lending/ borrowing (\% GDP) improves by } \\
\text { at least 0.5 percentage points }\end{array}$ \\
\hline $\begin{array}{l}\text { Government } \\
\text { expenditure (total) }\end{array}$ & EXP_P & $\begin{array}{l}\text { Normalized continuous variable, improve- } \\
\text { ment/deterioration of government expenditure (\% } \\
\text { GDP), in percentage points }\end{array}$ \\
\hline $\begin{array}{l}\text { General public } \\
\text { services }\end{array}$ & PUB_SER & $\begin{array}{l}\text { Normalized continuous variable, percentage share } \\
\text { in total government expenditure }\end{array}$ \\
\hline National defence & DEFENCE & $\begin{array}{l}\text { Normalized continuous variable, percentage share } \\
\text { in the total government expenditure }\end{array}$ \\
\hline $\begin{array}{l}\text { Public order and } \\
\text { security }\end{array}$ & SECURITY & $\begin{array}{l}\text { Normalized continuous variable, percentage share } \\
\text { in total government expenditure }\end{array}$ \\
\hline Economic affairs & ECON_AF & $\begin{array}{l}\text { Normalized continuous variable, percentage share } \\
\text { in total government expenditure }\end{array}$ \\
\hline $\begin{array}{l}\text { Environmental } \\
\text { protection }\end{array}$ & ENVIRON & $\begin{array}{l}\text { Normalized continuous variable, percentage share } \\
\text { in total government expenditure }\end{array}$ \\
\hline Housing policy & HOUSING & $\begin{array}{l}\text { Normalized continuous variable, percentage share } \\
\text { in total government expenditure }\end{array}$ \\
\hline Health & HEALTH & $\begin{array}{l}\text { Normalized continuous variable, percentage share } \\
\text { in total government expenditure }\end{array}$ \\
\hline
\end{tabular}




\begin{tabular}{|l|l|l|}
\hline \multicolumn{1}{|c|}{ Variable } & \multicolumn{1}{c|}{ Name } & \multicolumn{1}{c|}{ Coding } \\
\hline $\begin{array}{l}\text { Culture, leisure } \\
\text { industry, religion }\end{array}$ & CULTURE & $\begin{array}{l}\text { Normalized continuous variable, percentage share } \\
\text { in total government expenditure }\end{array}$ \\
\hline Education & EDUC & $\begin{array}{l}\text { Normalized continuous variable, percentage share } \\
\text { in total government expenditure }\end{array}$ \\
\hline Social asistance & SOCIAL & $\begin{array}{l}\text { Normalized continuous variable, percentage share } \\
\text { in total government expenditure }\end{array}$ \\
\hline
\end{tabular}

Source: [Postuła, Tomkiewicz, 2018].

In the above model, two variables reached the level of 0.05: expenditure on defence and expenditure on housing policy. These two variables have a negative impact on the probability of fiscal adjustment, i.e. improvement of the original budget balance by at least $0.5 \%$. Another important variable, amounting to 0.1 , represents the share of expenditure on security and public order. Higher than the average share of this expenditure in the total government expenditure increases the likelihood of fiscal adjustment.

\section{Description of obtained results}

The results of the conducted model research did not confirm a dependence between advancement in the implementation of performance budgeting, fiscal adjustment and the structure of expenditure (see: tables 2 and 3).

TABLE 2

First estimation of dependence model

\begin{tabular}{|l|c|c|c|c|c|c|}
\hline \multicolumn{1}{|c|}{ Variable } & $\begin{array}{c}\text { Coeffi- } \\
\text { cient }\end{array}$ & $\begin{array}{c}\text { Standard } \\
\text { error }\end{array}$ & Z statistic & P-value & $\begin{array}{c}\text { 95\% Confidence } \\
\text { Interval }\end{array}$ & Variable \\
\hline $\begin{array}{l}\text { Total ex- } \\
\text { penditure }\end{array}$ & -.65163 & .60126 & -1.08 & .2785 & -1.83007 & .52682 \\
\hline $\begin{array}{l}\text { General public } \\
\text { services }\end{array}$ & -.04402 & .79740 & -.06 & .9560 & -1.60690 & 1.51886 \\
\hline $\begin{array}{l}\text { National } \\
\text { defence }\end{array}$ & $-1.81173^{* * *}$ & .66220 & -2.74 & .0062 & -3.10963 & -.51383 \\
\hline $\begin{array}{l}\text { Public order } \\
\text { and security }\end{array}$ & 1.05193 & .72048 & 1.46 & .1443 & -.36018 & 2.46405 \\
\hline $\begin{array}{l}\text { Economic } \\
\text { affairs }\end{array}$ & -.32410 & .44170 & -.73 & .4631 & -1.18982 & .54162 \\
\hline $\begin{array}{l}\text { Environmental } \\
\text { protection }\end{array}$ & -.62397 & .47758 & -1.31 & .1914 & -1.56001 & .31207 \\
\hline Housing policy & $-1.57105^{* *}$ & .63935 & -2.46 & .0140 & -2.82415 & -.31795 \\
\hline
\end{tabular}




\begin{tabular}{|l|c|c|c|c|c|c|}
\hline \multicolumn{1}{|c|}{ Variable } & $\begin{array}{c}\text { Coeffi- } \\
\text { cient }\end{array}$ & $\begin{array}{c}\text { Standard } \\
\text { error }\end{array}$ & Z statistic & P-value & $\begin{array}{c}\text { 95\% Confidence } \\
\text { Interval }\end{array}$ & Variable \\
\hline Health & .77236 & .87788 & .88 & .3790 & -.94825 & 2.49298 \\
\hline Culture & -.60845 & .70308 & -.87 & .3868 & -1.98645 & .76956 \\
\hline Education & -.29718 & 1.08384 & -.27 & .7839 & -2.42146 & 1.82710 \\
\hline
\end{tabular}

Source: [Postuła, Tomkiewicz, 2018] on the basis of model research.

Final results of extended model

TABLE 3

\begin{tabular}{|l|c|c|c|c|c|c|}
\hline \multicolumn{1}{|c|}{ Variable } & Coefficient & $\begin{array}{c}\text { Standard } \\
\text { error }\end{array}$ & Z statistic & P-value & \multicolumn{2}{c|}{$\begin{array}{c}\text { 95\% Confidence } \\
\text { Interval }\end{array}$} \\
\hline National defence & $-1.17654^{* *}$ & .53945 & -2.18 & .0292 & -2.23384 & -.11925 \\
\hline $\begin{array}{l}\text { Public order and } \\
\text { security }\end{array}$ & $1.06680^{*}$ & .55212 & 1.93 & .0533 & -.01534 & 2.14894 \\
\hline Housing policy & $-1.66726^{* * *}$ & .57675 & -2.89 & .0038 & -2.79768 & -.53684 \\
\hline
\end{tabular}

Source: [Postuła, Tomkiewicz, 2018] on the basis of the model research.

Additionally, the obtained results indicate that the factors which influence the level of fiscal adjustment in the analysed countries can be divided into stimulants and destimulants. This makes it possible to determine the strength and direction of the impact of the specified variables on fiscal situation. Thanks to this, the process of finance management can be streamlined and focused on activities aimed at enhancing the financial situation of the analysed countries as regards fiscal adjustment. Among the factors which enable successful fiscal adjustment in the studied countries are higher expenditures on security. An increase in the level of these variables improves the likelihood of fiscal adjustment exceeding 0.5\% [Postuła, Tomkiewicz, 2018]. In the process of public finance management and fiscal adjustment, the expenditure policies of the eurozone countries in question should focus chiefly on this category of expenditures (see: charts 1 and 2).

If we juxtapose the above results with information regarding performance budgeting and, in particular, in what spheres of expenditure this instrument may be applied, it would be difficult to determine whether the hypothesis presented in the introduction is correct. The conducted model research does not allow for an unequivocal conclusion whether the hypothesis is true. However, it confirms that fiscal adjustment cannot be modelled, but depends on the political decisions made by individual countries. The two identified groups of expenditures: on defence and housing policies, have a rigid character and cannot be part of fiscal consolidation in the short term. 
CHART 1

Share of expenditure on defense, housing and security and fiscal adjustment in euro area countries in 2015



Source: author's own work on the basis of model research.

CHART 2

Average share of expenditure on public safety in 19 euro area countries and fiscal adjustment

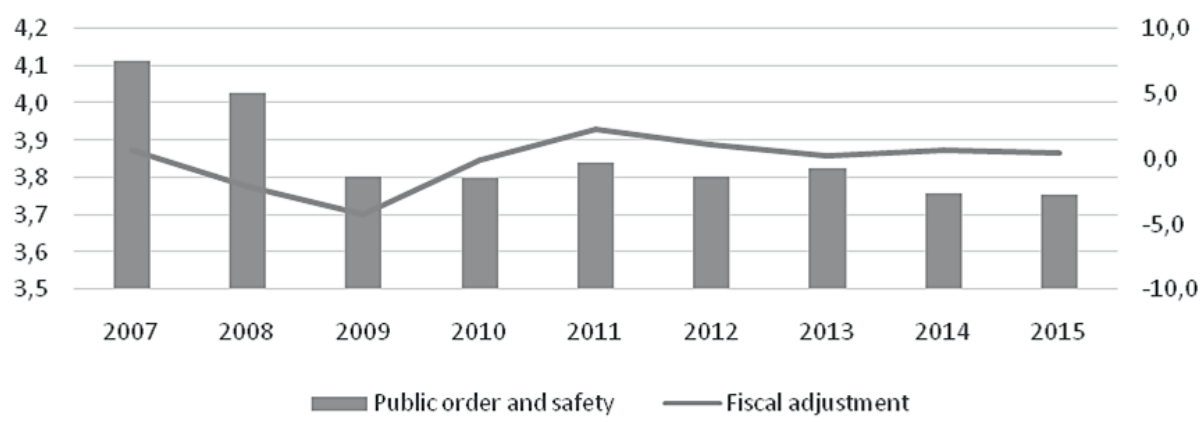

Source: author's own work on the basis of model research.

\section{Conclusions}

Compliance with the criteria of the nominal convergence ensuing from the Maastricht Treaty provisions does not constitute the ultimate aim of economic policies, but is a rational means of ensuring steady and sustainable economic development and robust public finances in medium and long-term perspective. To overcome the 
problems and improve the quality of fiscal policy it is necessary to use innovative, forward-looking - but also tailor-made - instruments of public management.

The conducted research shows that fiscal authorities need to take into consideration the specific influence of the time dimension and the level of fiscal imbalance in the public sector when making decisions about the dimensions and structure of expenditures. Unfortunately, the choices regarding the allocation and consolidation of public spending do not seem to be directly dependent on the advancement in the implementation of performance budgeting. This may result from the rigid character of some of the public expenditures, which involve multi-annual commitments that cannot be changed, or even amended. Effective changes of the structure and dimensions of public expenditure that would affect the dynamics of growth are mediumterm processes.

\section{References}

Baltagi B.H., 2003, Econometric Analysis of Panel Data, John Wiley \& Sons Ltd, The Atrium, England.

Boris G., 2014, Implications of public debt on economic growth and development. A European perspective, "IEB Int. J. Finance", no. 9, p. 42-61.

Dallago B., 2016, One Currency, Two Europes: Towards a Dual Eurozone, World Scientific Publishing, Singapore.

Dell'Erba, Mattina, 2013, Roitman Pressure or Prudence? Tales of Market Pressure and Fiscal Adjustment, IMF.

European Commission, 2010, Public Finances in EMU - 2010, Publications Office of the European Union, Luxembourg.

European Commission, 2015, Report on Public Finances in EMU, Publications Office of the European Union, Luxembourg.

European Union, 2017, Reflection paper on the deepening of the economic and monetary union, European Commission, Brussels, 32 May 31.

Fatas A., Mihov I., 2003, On Constraining Fiscal Policy Discretion in EMU, "Oxford Review of Economic Policy", vol. 19, iss. 1, p. 112-131, DOI: 10.1093/oxrep/ 19.1.112.

Galbraith J.K., 2016, Welcome to the Poisoned Chalice: The Destruction of Greece and the Future of Europe, Yale University Press, New Haven, London.

Greene W.H, 2002, ECONOMETRIC ANALYSIS, New York University.

Griliches Z., Intriligator M.D., 2007, Handbook of Econometrics, vol. 2 , Elsevier.

Hall P.A., 2014, Varieties of Capitalism and the Euro Crisis, "Journal of West European Politics", vol. 37, iss. 6, p. 1223-1243.

OECD, 2003, Enhancing the Cost Effectiveness of Public Spending, "Economic Outlook", vol. 02 , no. 74 .

OECD, 2007, Economic Outlook, June 2007, Chapter IV. Fiscal Consolidation: Lessons from past experience, OECD, Paris. 
OECD, 2009, Economic Outlook, March 2009, Chapter III. The Effectiveness and Scope of Fiscal Stimulus, OECD, Paris, http://www.oecd-ilibrary.org/economics/oecdeconomic-outlook_16097408 [date of entry: 03.04.2018].

OECD, 2012, Restoring Public Finances, 2012 Update, OECD Publishing, Paris.

OECD, 2015, The state of public finances 2015: strategies for budgetary consolidation and reform in OECD country.

OECD, 2018, Economic Outlook 100 database, https://stats.oecd.org/index.aspx?Data SetCode=EO [date of entry: 01.04.2018].

Postuła M., 2017, Finanse publiczne w architekturze wspótczesnej gospodarki. Teoria a polska praktyka gospodarcza, Difin, Warszawa.

Postuła M., Tomkiewicz J., 2018, Wplyw budǐetu zadniego na dostosowanie fiskalne, Working Paper.

Robinson M., 2006, Does Performance Budgeting Work?: An Analytical Review of the Empirical Literature, IMF Working Paper, no. 05/210.

Robinson M., 2016, The coverage of aggregate expenditure ceilings, "OECD Journal on Budgeting", vol. 2015, iss. 1, DOI: 10.1787/budget-15-5jm3rx2 qbr28.

Romp W., de Haan J., 2007, Public capital and economic growth: A critical survey, "Perspektivender Wirtschatftspolitik", no. 8, p. 6-52.

Shrithongrung A., Kriz K., 2014, The impact of subnational fiscal policies on economic growth: A dynamic analysis approach, "J. Policy Anal. Manag.", vol. 33, pp. 912-928.

Sly, N., Weber, C., 2013, International Fiscal Policy Coordination and GDP Comovement, CESifo Working Paper no. 4358, www.CESifo-group.org/wp. 